\title{
Occupational injury prevention research: progress and priorities
}

\author{
N A Stout, H I Linn
}

Injury Prevention 2002;8(Suppl IV):iv9-iv14

See end of article for authors' affiliations

.....................

Correspondence to:

Dr N A Stout, Division of

Safety Research, National

Institute for Occupational

Safety and Health, 1095

Willowdale Road,

Morgantown, West

Virginia 26505, USA;

nas5@cdc.gov

\begin{abstract}
The twentieth century witnessed remarkable reductions in the number and rate of occupational fatalities and injuries. However, many preventable injuries and deaths still occur. Barriers to progress in occupational injury prevention are discussed, along with strategies for overcoming them. In mining, the frequency of death has dramatically declined over the century. The latest figures from the BLS indicate that less than 6000 worker deaths from injury occurred in 2000. Catastrophic events have prompted increased attention, resources, and action on workplace hazards and risks, resulting in sweeping changes, including new protective laws. Science based approaches to prevention have contributed to progress. Multidisciplinary collaboration among injury prevention researchers, and collaboration and cooperation among multiple sectors, have improved the relevance and application of injury prevention research and development. Barriers to further progress include lack of evaluation of the effectiveness of prevention strategies and technologies, including cost effectiveness; lack of widespread implementation of known, effective prevention; and lack of efficient transfer and implementation of prevention knowledge and products to the workplace. Evaluation and implementation of prevention efforts are most successfully achieved in partnership between researchers and the industry at risk, which requires outreach efforts on the part of the occupational research community.
\end{abstract}

n just a few short minutes on September 11, 2001, thousands of workers lost their lives, including hundreds of public safety workers, who were used to facing risks and putting their lives on the line. But many workers in occupations not usually known for the risk of sudden injury and death also perished. And since that day, the US and the world have been engaged in investigating how these events occurred, and discovering and implementing strategies to prevent similar occurrences in the future.

We in the occupational injury prevention business realize that over the next 12 months, the United States alone will lose perhaps twice the number of workers to sudden death as perished on September 11. However, we will lose them one or two at a time, in isolated events, separated by time and space. They will not shock the world and traumatize us as large scale catastrophes have done. When they occur one at a time, it is easier to lose sight of the enormity of the cumulative toll.

But occupational injuries and deaths continue to add up to an overwhelming and unacceptable toll-especially when we know that most such deaths are preventable. We all realize that we must learn from catastrophic events; but we must also learn from these other thousands of workplace deaths, and the millions of workplace injuries that continue to occur, largely one at a time, across all our nations.

The events of September 11 have changed us all, including those of us engaged in injury prevention research and practice. We are mindful of newly emergent risks and are compelled to study them, and to identify, evaluate, and implement a broad range of preventive measures to reduce the threat of catastrophic events. Looking back across the past century in the United States, we see evidence of the relation of large scale tragedy to heightened collective concern toward occupational injuries and the application of increased resources and efforts to prevent similar occurrences.

Before discussing that further, let us look back in time to put the notion of "progress" into some perspective. The awareness that we can and should take action to prevent traumatic injuries and deaths goes at least as far back as recorded human history.
In fact, included in the book of Deuteronomy, believed to have been written around 3500 years ago, are these words:

\begin{abstract}
"When you build a new house, make a parapet around your roof so that you may not bring the guilt of bloodshed on your house if someone falls from the roof." Holy Bible. Deuteronomy xxii, 8 (New International Version)
\end{abstract}

Today we not only put up guardrails or parapet walls to keep people from pitching over the sides of roofs, we tie them off with harnesses and fall arrest systems; we catch them in safety nets; we limit their exposure with controlled access zones; we educate them with training programs; and we manage them with safety programs, all of which are intended to reduce the risk of falls. Why then, when we have known for several thousand years that keeping people from falling off roofs is both possible and, in fact, the ethical thing to do-are people still falling off roofs, and being crushed by rolling tractors, and being struck by falling materials, and being electrocuted?

Are we implementing prevention measures that are not working? Have we evaluated them to see if they actually have an effect on worker safety? Are we failing to fully implement the prevention measures that we know are effective? What are the barriers to the implementation of existing injury prevention knowledge, and what do we need to do to overcome them?

These are the double themes of this paper: On the one hand, the twentieth century has witnessed remarkable reductions in the frequency and rate at which occupational injuries occur. We share our thoughts on some of the reasons why we have seen progress. On the other hand, far too many preventable injuries are still occurring. We also discuss what we believe are some of the principal barriers to further progress.

\section{PROGRESS IN REDUCING OCCUPATIONAL INJURIES}

Looking back over the past 100 years, the progress in reducing work injuries has been quite remarkable. Mining provides 


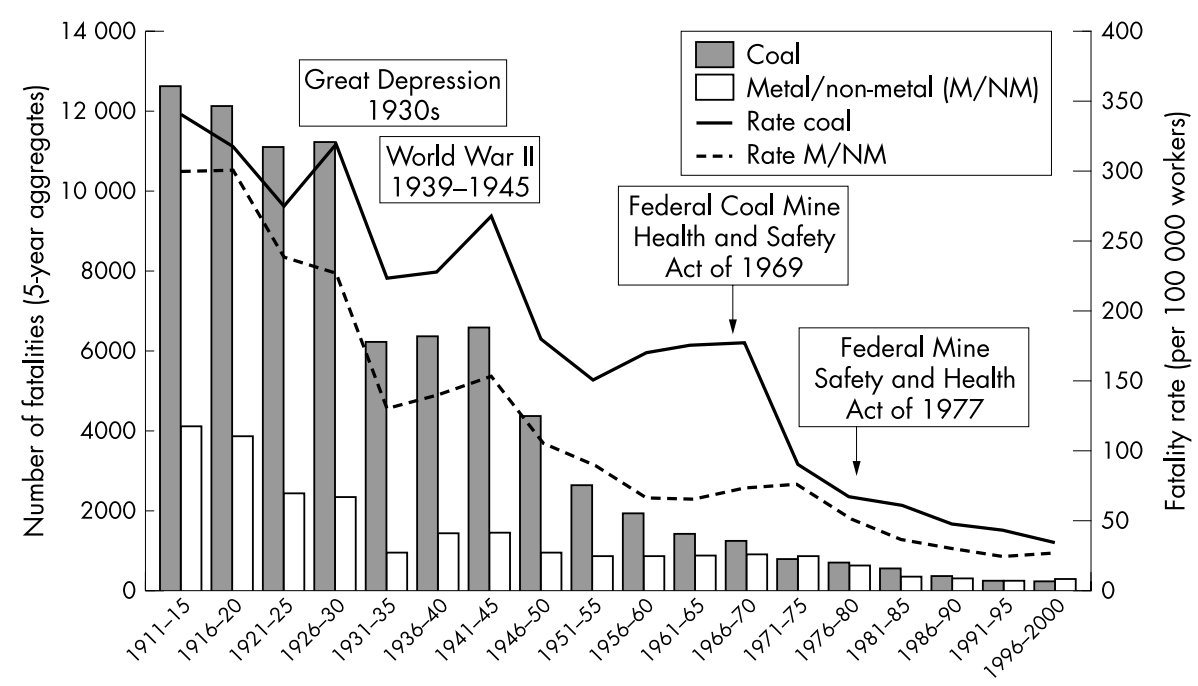

Figure 1 Number of fatalities (five year aggregates) and annual average fatality rates in the mining industry by commodity, 1911-2000. (Source: Data from the United States Bureau of Mines and the Mine Safety and Health Administration. Chart adapted from that presented in reference 1 and at internet address: http://www.cdc.gov/niosh/mining/data/images/hist1 1-00.gif)

perhaps the clearest evidence of the progress made in the US, partly because data have been collected for this industry for more than a century. Figure 1 shows that over 16600 US miners died during the five year period from 1911 to 1915, over 3300 deaths per year. During the period 1996-2000, 429 miners died, just over 85 deaths per year. From 1911 through 1997 the rate of deaths per 100000 miners plunged from well over 300 down to around 30. A number of events influenced these trends.'

Figure 2 depicts the dramatic reduction in mine disasters, events in which five or more miners were killed, for the entire twentieth century. There were over 900 miners killed in disasters in 1907 alone-that was the year of the explosion and fire at Monongah, West Virginia that killed 362 men. The incidence of mining disasters dropped to zero for each year from 1993 through 2000. The explosions that took 13 lives in an Alabama coal mine last September was the first such disaster in US mines in nine years. Unfortunately, we do not have such comprehensive data on workplace fatalities and injuries in the other industry sectors for the same period of time.

However, for the US workforce overall, the National Safety Council (NSC) and the Bureau of Labor Statistics (BLS) in the US Department of Labor have estimated the numbers and rates of workplace fatalities since 1912 and 1913, respectively. NSC estimated that in 1912, there were somewhere between 18000 and 21000 worker deaths, ${ }^{2}$ whereas the BLS estimated 23000 industrial deaths in the year 1913. ${ }^{3}$ The methods used to estimate deaths are not comparable enough to plot each year, but today, we have much improved surveillance of occupational injury deaths.

The National Traumatic Occupational Fatalities (NTOF) surveillance system provides perhaps the best trend data covering the past two decades. ${ }^{4}$ Figure 3 shows a steady decrease in occupational injury death for this period in both the numbers (bars) and rates (lines) (NIOSH, unpublished data from NTOF, 1980-98). The Census of Fatal Occupational Injuries reports fewer than 6000 worker deaths in the US for the year $2000 .{ }^{5}$ We have also made substantial progress in past 16 years in reducing each of the leading causes of workplace death in the US: motor vehicles, homicide, machine related, falls, and electrocutions (NIOSH, unpublished data from NTOF, 198098).

\section{FUNDAMENTAL REASONS FOR PROGRESS}

In this section we present what we believe are some of the fundamental reasons we have made progress. First, catastrophic events with multiple fatalities produce a high tide of outrage and social concern that focuses attention, resources, and efforts on specific problems. Such catastrophes have prompted a heightened awareness that a high risk of injury or death at work is not an acceptable risk. They have also led to sweeping change, and huge strides in the development of preventive strategies, including legislation and regulation.

Mining catastrophes resulted in new protective laws and organizations. For example, the explosion at Monongah, West

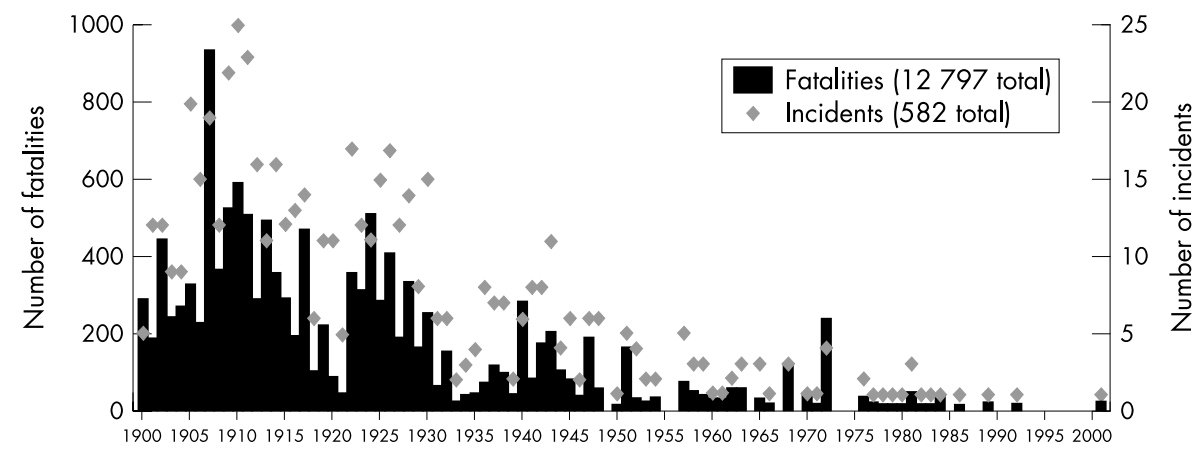

Figure 2 Mining disaster incidents and fatalities, 1900-2001 (a mining disaster is an incident with five or more fatalities). (Source: Data from the United States Bureau of Mines and the Mine Safety and Health Administration. Chart adapted from that presented at internet address: http://www.cdc.gov/niosh/mining/data/images/d_disall.gif) 


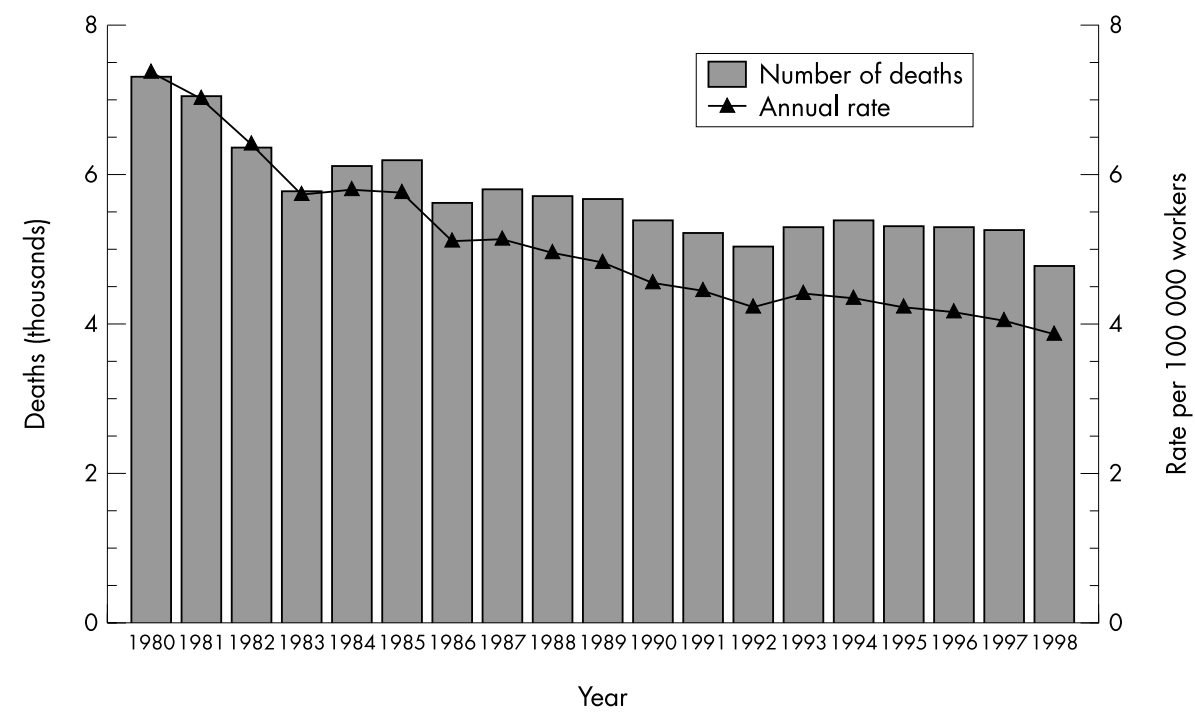

Figure 3 Distribution and rate of traumatic occupational fatalities by year, US, 1980-98 (all data for 1998 exclude New York State). (Source: Unpublished fatality data for 1980-98 are from the National Traumatic Occupational Fatalities Surveillance System, National Institute for Occupational Safety and Health, Centers for Disease Control and Prevention. Employment data are from the Current Population Survey, Bureau of Labor Statistics, Department of Labor)

Virginia, led to the formation of the US Bureau of Mines in 1910, and the 1968 explosion at Farmington, West Virginia, directly influenced the passage of the 1969 Coal Mine Safety and Health Act. The disaster at the Sunshine Mine near Kellogg, Idaho in 1972 led to the creation of the Mine Safety and Health Administration and the requirement that miners carry breathing devices. ${ }^{67}$

The horrible fire at the Triangle Shirtwaist Company in New York City in 1911 claimed 146 lives, mostly women who, in order to escape the flames, jumped from windows and ledges to their death on the streets below. This catastrophe brought sweeping reforms and new labor laws not just in New York City, but nationwide. ${ }^{8}$

The new legislation to address safety and health concerns in mining in 1969, also influenced and served as a model for the creation of the Occupational Safety and Health Act of 1970. The OSH Act created the Occupational Safety and Health Administration (OSHA) in the US Department of Labor to promulgate and enforce workplace safety and health regulations, and the National Institute for Occupational Safety and Health (NIOSH), in the (now) Department of Health and Human Services, to conduct occupational safety and health research for prevention. ${ }^{3}$ 9

Structural collapses during the construction process, such as the tragic collapse of the cooling tower at Willow Island in 1978 that killed 52 workers, and the collapse of the L'Ambiance Plaza in Connecticut in 1987 which killed 28 workers, both led to extensive analyses of construction processes and practices, and new guidelines to prevent future collapses. ${ }^{10}$

Catastrophic events have led to major prevention actions, such as increased regulation of the workplace, but the proactive, and sustained effort of occupational injury prevention researchers has also contributed to improved workplace safety.

Much of the recent progress we have seen would not have been possible without the application of science based problem solving methods to work injury.

The first important science based approaches to be brought to bear on occupational injury problems were the safety sciences-that is, safety engineering, industrial hygiene, and safety management. Most of the terrible mining disasters that occurred in the nineteenth and twentieth centuries resulted from methane and dust explosions and fires. Several critical engineering and management solutions worked together, within the context of regulatory requirements and enforcement, to reduce the risk of these catastrophic events: Explosion proof equipment and lights, and strict smoking control policies removed ignition sources from mine environments; and improved gas and dust control through ventilation, rock dusting, and other means kept explosive mixtures from developing in mine atmospheres. The development of respirators and mine rescue plans and teams have helped to increase the odds that miners can survive explosions and fires. These advances evolved largely as the products of science based assessments of mining environments and processes, as well as a reaction to large scale disasters. ${ }^{1311}$

A second important science based approach to prevention was applied to occupational injury a little later in the twentieth century. The public health approach, based on the scientific methods of epidemiology, has been applied around the world and very successfully to infectious diseases for centuries.

In a seminal 1949 article, John Gordon proposed the application of epidemiology and the public health approach to injury prevention, ${ }^{12}$ although it was not widely applied until several decades later. ${ }^{13} \mathrm{~A}$ brief outline of the public health model, as it applies to injury prevention, is provided here because it is a very useful framework for discussing progress in, as well as barriers to prevention. But more importantly, it is also the framework in which we see the greatest potential for significant future gains in occupational injury prevention.

The Public Health Model is essentially a problem solving framework that includes these phases:

- Identify and prioritize problems through injury surveillance

- Quantify and prioritize risk factors through analytic injury research

- Identify existing or develop new strategies to prevent occupational injuries, including evaluation and confirmation of effectiveness

- Implement the most effective injury control measures through dissemination and technology transfer

- Evaluate and monitor the results of intervention efforts. ${ }^{14}$ Applying the methods of public health prevention to injuries has not only expanded the scientific basis for prevention efforts, but has also been critical in the recognition and acceptance of occupational injuries as a public health issue. 




Figure 4 Rate of traumatic occupational fatalities by year for leading causes of death, 1980-98. Trend lines were calculated using the linear regression function in Microsoft Excel 2000. (Source: Unpublished fatality data for 1980-98 are from the National Traumatic Occupational Fatalities Surveillance System, National Institute for Occupational Safety and Health, Centers for Disease Control and Prevention. Employment data are from the Current Population Survey, Bureau of Labor Statistics, Department of Labor)

A third reason we have seen progress is the increase in cooperation and collaboration among the sectors of society (for example, government, industry, labor, etc) and among those trained in the variety of disciplines that study work injuries. It takes the knowledge and tools of multiple disciplines to effectively address all of the phases of the public health model. Collaboration between public health scientists, safety scientists, and social scientists establishes necessary links between the descriptive and analytic work on the one hand and the technologies of prevention on the other. As a result, the findings of surveillance and analytic research can drive and inform the development of prevention knowledge and technology.

Collaboration involving multiple sectors of society is critical as well. Researchers who partner with industry and labor, and other organizations that serve them, are provided the opportunity to study workplace hazards and prevention in natural experiments, and utilize "living laboratories", in real work settings to test and evaluate prevention measures. Additionally, such collaborations can facilitate adoption and implementation of effective prevention measures, through the sharing of information and ideas, the early buy in, and resultant joint ownership of research studies and preventive solutions.

Much of the progress in reducing work injury and fatality in the US can be attributed to the application of science based approaches, including the safety sciences and public health approaches, and the increase in collaboration among disciplines and sectors. It has also taken the shock of catastrophic events to stir us to action. Of course, social and economic forces, such as the employment shift from manufacturing activity to service and retail activities, and the worker safety and health focus of the US labor movement, have also contributed to this decline. Despite the progress, however, far too many injuries and deaths among workers still occur.

BARRIERS AND STRATEGIES FOR FUTURE PROGRESS

Overall, the frequency and rate of traumatic occupational fatalities are still declining, and they are declining for each of the leading causes of death. However, the rate of decline is not consistent across industries or causes of death. When you fit a linear regression line to the trend of fatality rates for the leading causes of occupational injury death (fig 4), you can see that the rate of occupational death is dropping much more rapidly for motor vehicles, machine related deaths, and electrocutions, than for homicides and falls.

Figure 5 shows the trend line for the motor vehicle fatality rates within the industry sectors in which most occupational motor vehicle deaths occur. It is apparent that the decrease in motor vehicle deaths in the transportation, communication, and public utility industry (Transport) is largely responsible for the overall decline. However, the motor vehicle rates in other sectors have changed very little in 16 years.

The trend of fatality rates for fall related deaths by industry shows rates are on a downward track for construction, where there has been much research interest and many resources have been applied for prevention. However, fall death rates have actually increased in agriculture and mining (fig 6).

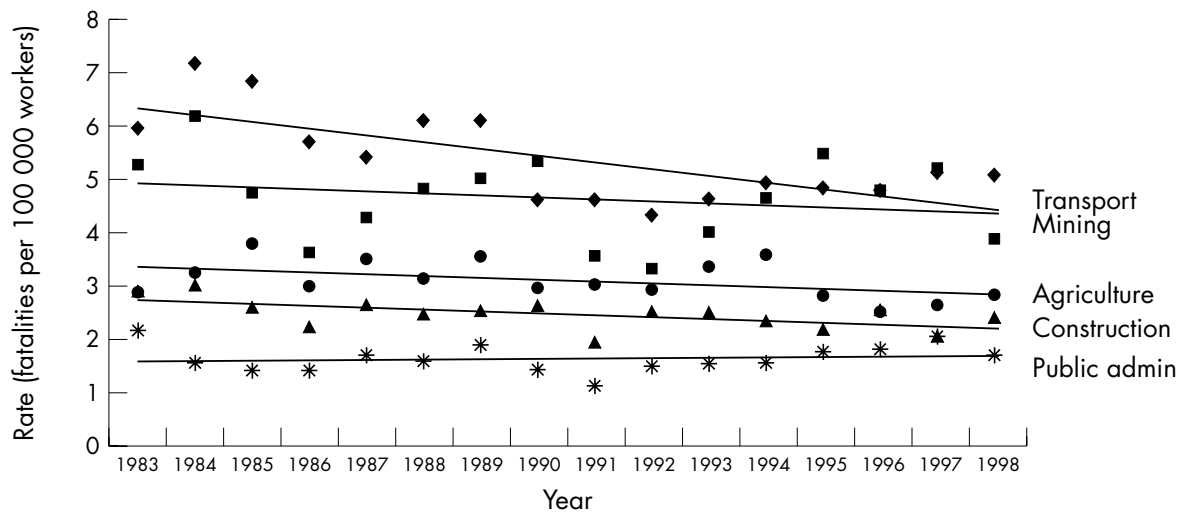

Figure 5 Rate of occupational motor vehicle deaths by year for select industries, 1983-98. Trend lines were calculated using the least squares linear regression function in Microsoft Excel 2000. (Source: Unpublished fatality data for 1980-98 are from the National Traumatic Occupational Fatalities Surveillance System, National Institute for Occupational Safety and Health, Centers for Disease Control and Prevention. Employment data are from the Current Population Survey, Bureau of Labor Statistics, Department of Labor) 


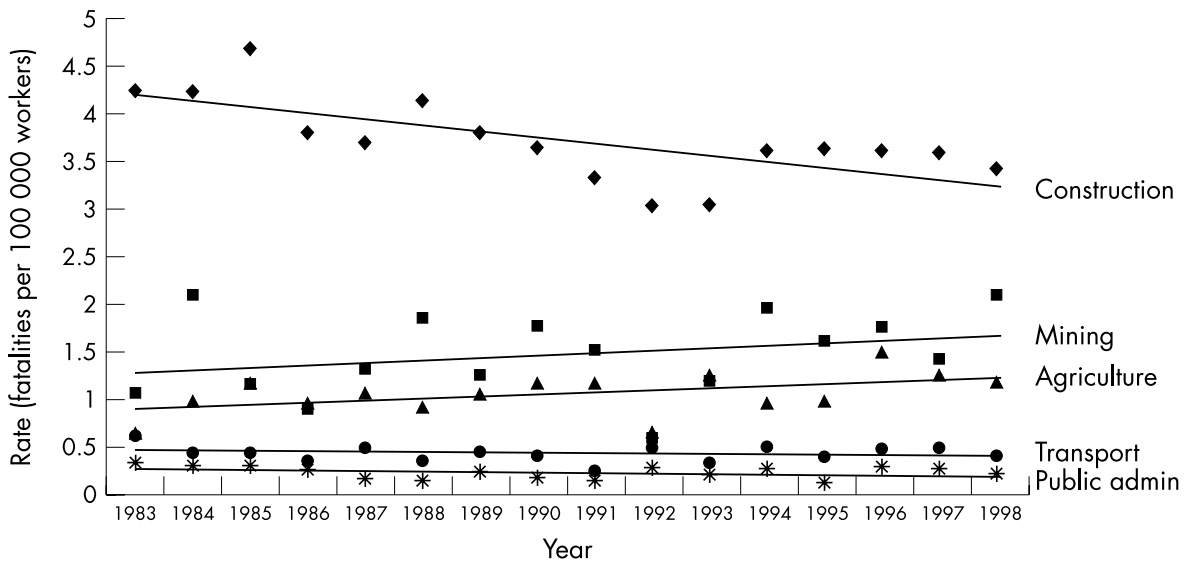

Figure 6 Rate of occupational fall deaths by year for select industries, 1983-98. Trend lines were calculated using the least squares linear regression function in Microsoft Excel 2000. (Source: Unpublished fatality data for 1980-98 are from the National Traumatic Occupational Fatalities Surveillance System, National Institute for Occupational Safety and Health, Centers for Disease Control and Prevention. Employment data are from the Current Population Survey, Bureau of Labor Statistics, Department of Labor)

Why has the risk of dying from a motor vehicle crash or a fall decreased in some sectors, and not changed and even increased in others? This suggests that our tendency to set priorities and to focus resources on specific injury problems in specific industry sectors may be working to prevent injuries in those sectors. But it suggests the counterpoint, as well-that the lack of focus on specific problems in specific industry sectors may result in no change at best, and may even result in increasing injuries. More importantly, perhaps, is the implication that there are few mechanisms, strategies, or incentives in place for transferring, for example, the fall protection knowledge gained in construction to other sectors where fall injuries occur and may be on the rise.

We now present what we consider to be other, principal barriers to further progress in occupational injury prevention. First, although there are many preventive programs, strategies, controls, and technologies available, very few have been fully evaluated to determine whether or not they are effective. Programs or strategies are often implemented without efforts to determine whether they are having an effect. Too often we skip that very important component of the public health model-evaluation, and we have no evidence of whether our efforts are making a difference or not.

Second, there are many prevention approaches that are known to be effective that have not been widely implemented in all workplaces where they might. There are a variety of reasons why effective prevention is not implemented.

One is that implementation relies on the decisions and behaviors of many people-employers, workers, policymakers, etc. The processes by which people make decisions and changes are not always simple and straightforward and are influenced by many factors. Behavioral, social, and communications science are all crucial to understanding these psychological and organizational barriers to implementing prevention.

Another reason is that implementation may not be viewed as cost effective. Also, cost is not always considered in the design of prevention measures. Too frequently, cost-benefit analyses are not conducted on newly developed prevention efforts. This is an integral part of the evaluation component of the public health model that is underemphasized.

Third, information about new prevention programs, strategies, technologies, and products is often slow to diffuse through the social networks of those whose decisions can result in the implementation of prevention.

This is a huge research question all of its own: how can and how does research inform prevention? We know it does, but we do not know enough about the process and mechanisms to effectively influence or modify them to increase the timely adoption of effective prevention. The rate of adoption of prevention measures is sometimes very slow or never becomes widespread.

One model used to describe the adoption of new ideas or technologies within a given population over time is the innovation diffusion model. ${ }^{15}$ This model describes the rate at which innovations are adopted, and the roles of various types of individuals within the populations. This theory holds that a key to being able to influence a higher rate of adoption would be to identify and influence the early adopters, who in turn influence the later adopters, and ultimately the shape of the adoption curve itself. If the innovation in question is an effective preventive strategy, the faster the rate of adoption, the more injuries prevented and lives saved.

Occupational injury prevention researchers need to take more responsibility, and more action, to understand and affect the transfer and adoption of our research and prevention knowledge and products by those whose health and lives we strive to protect. This is our most immediate barrier and challenge.

\section{CONCLUSIONS}

Over the past 100 years, dramatic reductions in workplace injuries and deaths have occurred. Recent trends continue to show reductions in numbers and rates of fatal occupational injuries. We can attribute successful prevention to a collective response to catastrophic events. We can cite the positive, sustaining force of a science based approach to prevention, as well as the importance of multidiscipline and multisector cooperation and collaboration. However, further progress may hinge on how effectively we can address the barriers to prevention that remain. Among these barriers are: the lack of sufficient prevention evaluation research, including cost-benefit analysis, and the challenge of fostering the adoption and implementation of controls that we know work.

We have learned through increasingly comprehensive surveillance systems what has actually happened to whom, when, where, and in what jobs and industries. We have investigated and analyzed these incidents in greater detail to determine what specific circumstances, events, and characteristics combine to produce injuries to workers. We have deduced means of interrupting the flow of events or altering the design of a workplace, or introducing new protective technology that can ultimately prevent injuries. We have published this information, and even proactively marketed it in some cases. We have recognized injuries as a public health problem and we 
have applied the scientific methods of public health to find solutions. And we are encouraged by our progress. But injuries continue to occur; injuries that we know are predictable and preventable.

Have we fully embraced the entire public health approach? Have we, the occupational safety research community, accepted as our responsibility the scientific evaluation of our prevention knowledge and products and the transfer and implementation of effective prevention measures? Or are we thinking that is someone else's responsibility?

The difficult truth is, the occupational injury research community cannot effectively evaluate and implement prevention strategies on its own; neither can industry, nor employers, nor workers at risk. We all have to do it together in partnership. But it is the responsibility of the occupational injury research community to reach out, to ensure we are completing all of the phases of the pubic health approach. Our publications, presentations, and even our new protective technologies are not the end result, but an intermediary step. From here, we still have an important responsibility: to find the means to apply what we know so that the real end result is the worker that goes home alive and safe at the end of the day. We should be proud of, and encouraged by our progress, but we must also recognize, and step up to, the challenges that remain.

\section{Authors' affiliations}

N A Stout, H I Linn, Division of Safety Research, National Institute for Occupational Safety and Health, 1095 Willowdale Road, Morgantown, West Virginia 26505, USA

\section{REFERENCES}

1 Centers for Disease Control and Prevention. Achievements in public health, 1900-1999: improvements in workplace safety-United States, 1900-1999. MMWR 1999:48:461-9.

2 National Safety Council. Injury facts. Itasca, IL: National Safety Council, 2000:44.

3 Corn JK. Response to occupational health hazards: a historical perspective. New York, NY: Nostrand Reinhold, 1992:4-5.

4 Marsh SM Layne LA. Fatal injuries to civilian workers in the United States, 1980-1995, national profile. DHHS (NIOSH) Publication Number 2001-129. Cincinnati, OH: NIOSH.

5 US Department of Labor, Bureau of Labor Statistics. USDL News: National census of fatal occupational injuries in 2000, USDL 01-261 (press release), August 14, 2001. Internet address: http://stats.bls.gov/ iif/oshwc/cfoi/cfnr0007.pdf (last accessed 7/12/2002).

6 National Research Council. Toward safer underground coal mines. Washington, DC: National Academy Press. 1982:52-5.

7 Mine Safety and Health Administration. Mine disasters-an exhibition (website). Internet address: http://www.msha.gov/DISASTER/ DISASTER.HTM (last accessed 7/12/2002)

8 Stein L. The triangle fire. Ithaca, NY: Cornell University Press, 2001

9 Williams-Steiger. Occupational Safety and Health Act of 1970. Public Law 91-596.

10 Kaminetzky D. Design and construction failures: lessons from forensic investigations. New York, NY: McGraw-Hill, 1991:78-85, 167-70.

11 Gregory CE. A concise history of mining. New York, NY: Pergamon Press, 1980:185.

12 Gordon JE. The epidemiology of accidents. Am J Public Health 1949;39:504-15

13 Stout $\mathbf{N}$, Linn $\mathrm{H}$. From strategy to reality: 25 years of planning and progress in occupational injury research. Injury Prevention $2001 ; 7$ (suppl l): $111-14$

14 Stout N, Borwegen W, Conway G, et al. Traumatic occupational injury research needs and priorities: a report by the NORA Traumatic Injury Team. Cincinnati, OH: US Department of Health and Human Services, Centers for Disease Control and Prevention, National Institute for Occupational Safety and Health, 1998:5.

15 Rogers EM. Diffusion of innovations, 4th edn. New York, NY: The Free Press, 1995:5-12. 